\title{
Association of homeobox B13 (HOXB13) gene variants with prostate cancer risk in an Iranian population
}

\author{
Raheleh Roudi ${ }^{1}$, Hosein Nemati ${ }^{2}$, Mahsa Rastegar Moghadam ${ }^{3}$, Mehdi Sotoudeh ${ }^{4}$, Behzad Narouie $^{5}$ \\ Azadeh Shojaei*3
}

Received: 19 Dec 2017

Published: 7 Oct 2018

\begin{abstract}
Background: Prostate cancer is a complex condition in which both genetic and environmental factors concomitantly contribute to the tumor initiation and progression. Recently, HOXB13 has been proposed as a susceptibility gene for prostate cancer.

Objective: The present study was conducted to determine the existence of potential variations in HOXB13 gene in Iranian men with prostate cancer $(\mathrm{PCa})$ compared to benign prostatic hyperplasia $(\mathrm{BPH})$ cases.

Methods: HOXB13 genetic status was screened in 51 samples, including 21 blood and tissue of PCa cases, and compared to 30 cases affected by BPH using PCR/sequencing. Then, the existence of potential association was investigated between genomic DNA alterations in blood and tissue PCa specimens.

Results: Analysis of BPH tissues showed single nucleotide variations c.366C $>$ T (rs) or c.513T $>$ C (rs9900627) in exon 1, but not in exon 2. Evaluation of PCa tissues revealed 2 cases with both synonymous c.366C $>\mathrm{T}$ and c.513T $>\mathrm{C}$ variants and 2 cases with the synonymous c.366C $>\mathrm{T}$ variant in exon 1 . The variants c.366C $>\mathrm{T}$ and c.513T $>\mathrm{C}$, simultaneously or separately, were found in blood samples of PCa patients. The novel variant c.127A $>$ G in exon 2 was detected in 1 PCa blood sample. Our analysis indicated a significant reciprocal correlation between HOXB13 mutation in the tissue and blood samples of PCa cases $(\mathrm{p}=0.02)$.

Conclusion: The variants in exon 2 of HOXB13 may influence the risk of prostate cancer. Also, evaluation of HOXB13 mutation may be considered as a novel marker for screening PCa. Further investigations are warranted to evaluate the clinical significance of HOXB13 in Iranian population.
\end{abstract}

Keywords: Prostate cancer, HOXB13, Benign prostatic hyperplasia, Variant, Iran

Conflicts of Interest: None declared

Funding: None declared

*This work has been published under CC BY-NC-SA 1.0 license.

Copyright $\subseteq$ Iran University of Medical Sciences

Cite this article as: Roudi R, Nemati H, Rastegar Moghadam M, Sotoudeh M, Narouie B, Shojaei A. Association of homeobox B13 (HOXB13) gene variants with prostate cancer risk in an Iranian population. Med J Islam Repub Iran. 2018 (7 Oct);32:97. https://doi.org/10.14196/mjiri.32.97

\section{Introduction}

Prostate cancer $(\mathrm{PCa})$ is considered the second most common malignancy after lung cancer in men and the sixth leading cause of cancer-related death worldwide (1). The 5-year survival rate in benign prostatic hyperplasia $(\mathrm{BPH})$ is about $100 \%$, but the occurrence of metastasis to distant organs would decrease to $31 \%$ in $\mathrm{PCa}$ (2).

Corresponding author: Dr Azadeh Shojaei, a_shojaei2007@yahoo.com

1. Oncopathology Research Center, Iran University of Medical Sciences, Tehran, Iran 2. Department of Genetics, Subdiscipline of Biology, Payame Noor University, Tehran, Iran

3. Department of Medical Genetics and Molecular Biology, Faculty of Medicine, Iran University of Medical Sciences, Tehran, Iran

4. Urology and Nephrology Research Center, Shahid Beheshti University of Medical Sciences, Tehran, Iran, \& Department of Urology, Shahid Beheshti University of Medical Sciences, Tehran, Iran

5. Department of Urology, Zahedan University of Medical Sciences, Zahedan, Iran
Depending on the tumor stage, therapeutic options can be different ranging from radiation therapy to radical prostatectomy for the benign localized tumor and antiandrogen therapy for metastatic types. It has been demonstrated that in the case of hormonal therapy, $20 \%$ to $30 \%$ of tumors will develop resistance and become more

$\uparrow$ What is "already known" in this topic:

Prostate cancer is a complex condition, in which both genetic and environmental factors concomitantly contribute to the tumor initiation and progression. Recently, HOXB13 has been proposed as a susceptibility gene for prostate cancer.

$\rightarrow$ What this article adds:

There is no data about the role of HOXB13 in development of $\mathrm{PCa}$ in Iranian men. This study showed that the variants in exon 2 of HOXB13 may influence the risk of prostate cancer. Also, evaluation of HOXB13 mutation may be considered as a novel marker for screening PCa. Further investigations are warranted to evaluate the clinical significance of HOXB13 in Iranian population. 
aggressive; they are known as castration-resistant prostate cancer (CRPC) (3).

HOXB13 is one of the members of HOX gene superfamily and possesses a broad range of expression patterns from low levels in colon and rectum to high levels in the normal prostate gland and prostate cancer (4, 5). HOX gene superfamily encodes homeoproteins as transcription factors having an important regulatory role in axial-regional differentiation during embryonic development, cell proliferation, and development of sex organs (6). After screening 17q21-22 region as a susceptibility locus for prostate cancer performed by Ewing et al. at the beginning of 2012, HOXB13 was introduced as a high-risk gene for PCa susceptibility (7). The G84E (rs138213197) is a rare and recurrent mutation on a highly conserved domain of HOXB13 protein that was observed in germline DNA of European descent men with prostate cancer (8). Subsequent studies showed a higher frequency of HOXB13 G84E mutation in positive history and early-onset of $\mathrm{PCa}$ compared to healthy individuals $(9,10)$. A previous experiment demonstrated HOXB13 G135E as a novel mutation conferring the risk of $\mathrm{PCa}$ in Chinese men (11). It has been reported that overexpression of HOXB13 is correlated with advanced pathologic stage of the disease, Gleason's score, the involvement of lymph node, and shorter survival rate (12). It has also been shown that HOXB13 can be a potential candidate for clinical application by itself, or in combination with other markers (13).

The accumulating evidence indicates the pivotal role of mutation or dysregulation of HOXB13 gene in $\mathrm{PCa}$, but there is no convincing data about this gene. Additionally, there is no data about the role of HOXB13 in development of PCa in Iranian men (14). The present study aims at exploring the presence of HOXB13 mutations in patients with PCa compared to BPH patients.

\section{Methods \\ Study population and clinical sample collection}

A total of 56 samples (21 PCa cases and 35 BPH cases) were recruited from a major referral urology-nephrology center in Iran (Labbafinezhad Hospital) from July 2015 to April 2016. Written informed consent was obtained from all patients. Tissue specimens were obtained by radical prostatectomy or transurethral resection (TURP) and were immediately snap-frozen in liquid nitrogen and stored at $80^{\circ} \mathrm{C}$ until use. For each PCa patient, venous blood samples were collected in ethylene diamine tetra acetic acid (EDTA)-containing tubes and stored at $-80^{\circ} \mathrm{C}$ for DNA extraction. The specimens were obtained before any treatment modalities, including radiotherapy and chemotherapy. Clinicopathologic data of enrolled patients, including age, history of PCa in the family, smoking, serum prostate-specific antigen (PSA) level, and Gleason score were collected and recorded. This study was approved by the Ethical Committee of Iran University of Medical Sciences.

\section{DNA extraction of frozen tissues and blood samples}

To analyze HOXB13 gene in PCa and BPH tissues and patients' blood, genomic DNA was extracted using the YT9030 kit (Yektatajhiz, Tehran, Iran). TG1 buffer and Proteinase $\mathrm{K}$ were added to tissues and incubated at $60^{\circ} \mathrm{C}$ overnight. After finishing the tissue lysis, TG2 buffer was added and incubated at $70^{\circ} \mathrm{C}$ for 10 minutes. Then, ethanol was added and the mixture was transferred to the column and after 2 times of washing, the DNA was precipitated. Genomic DNA extraction of blood samples was performed using the YT9040 kit (Yektatajhiz, Tehran, Iran), according to manufacturer's instructions. Briefly, $\mathrm{BG}$ buffer and Proteinase $\mathrm{K}$ were added to the blood sample and incubated at $60^{\circ} \mathrm{C}$ for 15 minutes. Then, ethanol was added and the mixture was transferred to the column and after 2 times of washing, DNA was precipitated. Quality and quantity of DNA were evaluated using gel electrophoresis and Nanodrop, respectively.

\section{Genotyping of HOXB13 gene and sequence analysis}

Two exons of HOXB13 gene (NM_006361.5) were screened for genetic variations by $\overline{P C R}$. Each PCR reaction with $25 \mu \mathrm{L}$ reaction mixture contained $2.4 \mu \mathrm{L}$ of $2 \times$ reaction buffer, $2 \mu \mathrm{L}$ of genomic DNA templates, 0.1 $\mu \mathrm{L}$ of Taq DNA polymerase $(5 \mathrm{U} / \mu \mathrm{L}), 1 \mu \mathrm{L}$ of each primer, $1.5 \mu \mathrm{L}$ of $\mathrm{MgCl} 2(50 \mathrm{Mmol})$, and $0.5 \mu \mathrm{M}$ of $\mathrm{dNTP}$ (10Mm). After initial denaturation at $94{ }^{\circ} \mathrm{C}$ for $3 \mathrm{~min}, 32$ PCR cycles were performed using Biorad thermocycler (Bio-Rad Laboratories, Hercules, CA, USA); each cycle for exon 1 included denaturation at $94^{\circ} \mathrm{C}$ in $30 \mathrm{~s}$, annealing at $64{ }^{\circ} \mathrm{C}$ in $30 \mathrm{~s}$, extension at $72^{\circ} \mathrm{C}$ for $1 \mathrm{~min}$, and final extension at $72^{\circ} \mathrm{C}$ in $10 \mathrm{~min}$, respectively. All cycling steps of exon 2 are the same as exon 1 except annealing at $62{ }^{\circ} \mathrm{C}$. PCR products were subjected to electrophoresis on agarose gel $(1.5 \%)$, followed by staining with green viewer $(3.5 \mu \mathrm{g} / \mathrm{mL})$ to verify the anticipated length of amplified fragments. Direct sequencing was used with primers (Table 1). Sequencing was done by MACROGEN Company in South Korea using a classic Sanger method with ABI.

\section{Statistical analysis}

The analysis of sequencing data was performed by mutation surveyor software (SoftGenetics, Pennsylvania, USA). All data were analyzed using SPSS software version 20 (SPSS, Chicago, IL, USA). The correlation between HOXB13 mutation and clinicopathological

Table 1. The sequence of HOXB13 primers for exon 1 and exon 2

\begin{tabular}{lcccc}
\hline Primer & Forward & Reverse & Product size (bp) & Tm ( ${ }^{\circ}$ C) \\
\hline EXON 1 & CGAGCTGGGAGCGATTTA & AGCTCCAAGTCTCCCTCCTC & 769 \\
EXON 2 & GCCTGTAGGGTGACCTGTGT & TCCGTCTCCCTGCACATACT & 522 \\
\hline
\end{tabular}


Table 2. Somatic HOXB13 variants detected in benign prostatic hyperplasia

\begin{tabular}{c|ccccc}
\hline $\begin{array}{c}\text { PATIENT } \\
\text { CODE }\end{array}$ & LOCATION & $\begin{array}{c}\text { CDNA ALTERA- } \\
\text { TION }\end{array}$ & RS NUMBER & CLASSIFICATION & VARIANT TYPE \\
\hline $\mathbf{A - 0 5}$ & Exon 1 & c.366C $>$ T & rs 8556 & Heterozygote & Synonymous \\
C-04 & Exon 1 & c.366C $>$ T & rs 8556 & Homozygote & Synonymous \\
D-04 & Exon 1 & c.513T $>$ C & rs9900627 & Heterozygote & Synonymous \\
D-11 & Exon 1 & c.366C $>$ T & rs 8556 & Heterozygote & Synonymous \\
H-04 & Exon 1 & c.513T $>$ C & rs 9900627 & Heterozygote & Synonymous \\
C-07 & Exon 1 & c.513T $>$ C & rs 9900627 & Heterozygote & Synonymous \\
\hline
\end{tabular}

Table 3. Somatic HOXB13 variants detected in prostate cancer patients

\begin{tabular}{|c|c|c|c|c|c|}
\hline $\begin{array}{l}\text { PATIENT } \\
\text { CODE }\end{array}$ & LOCATION & $\begin{array}{c}\text { CDNA ALTERA- } \\
\text { TION }\end{array}$ & RS NUMBER & CLASSIFICATION & VARIANT TYPE \\
\hline 1 & Exon 1 & $\begin{array}{l}\text { c. } 366 \mathrm{C}>\mathrm{T} \\
\text { c. } 513 \mathrm{~T}>\mathrm{C}\end{array}$ & $\begin{array}{c}\text { rs8556 } \\
\text { rs } 9900627\end{array}$ & Heterozygote & Synonymous \\
\hline 2 & Exon 1 & c. $366 \mathrm{C}>\mathrm{T}$ & rs 8556 & Heterozygote & Synonymous \\
\hline 4 & Exon 1 & c. $366 \mathrm{C}>\mathrm{T}$ & rs 8556 & Heterozygote & Synonymous \\
\hline 15 & Exon 1 & $\begin{array}{l}\text { c. } 366 \mathrm{C}>\mathrm{T} \\
\text { c. } 513 \mathrm{~T}>\mathrm{C}\end{array}$ & $\begin{array}{c}\text { rs } 8556 \\
\text { rs9900627 }\end{array}$ & Heterozygote & Synonymous \\
\hline
\end{tabular}

parameters were evaluated using Pearson's $\chi 2$ and Fisher's exact test. A p-value of $\leq 0.05$ was considered statistically significant.

\section{Results \\ Clinicopathological information and HOXB13 variations in BPH cases \\ The mean age of BPH cases was $71.3 \pm 1.6$ years (range $54-89$ years). Mean of PSA level in BPH samples was $3.96 \pm 0.69$ (range: 1 - 15). In the analysis of BPH tissues, six $(17.64 \%)$ of 34 cases had single nucleotide variation in exon 1, whereas no nucleotide change was found in exon 2. Among six, three samples were c.366C $>\mathrm{T}$ (rs8556) and other three had the c.513T $>\mathrm{C}$ (rs9900627) (Table 2).}

\section{Clinicopathological information and HOXB13} variations in PCa cases

The mean age of $\mathrm{PCa}$ patients was $63.67 \pm 1.9$ years $(50$ 83 years). The mean of PSA level in PCa cases was
17.16 \pm 4.28 (range: 5-83). Eight (38\%) and 4 (19\%) of PCa patients had Gleason score 6 and 7, respectively, whereas Gleason scores 8 and higher was found in 5 (24\%) of PCa samples.

Investigation of PCa tissue samples demonstrated that 4 $(19.04 \%)$ cases had single nucleotide variation in exon 1 . Among them, 2 cases had both synonymous c.366C $>\mathrm{T}$ (rs8556) and c.513T $>$ C (rs9900627) variants, and 2 cases displayed the synonymous c.366C $>\mathrm{T}$ variant (Table 3 ). Evaluation of $\mathrm{PCa}$ blood samples revealed that 9 (42.85\%) of cases had variant in exon 1 , whereas only 1 case showed variant in exon 2. The variants c.366C $>\mathrm{T}$ and c.513T $>\mathrm{C}$ were simultaneously found in 2 patients, c.366C $>\mathrm{T}$ was detected in 2 samples, and c.513T $>\mathrm{C}$ was seen in $4 \mathrm{PCa}$ patients (Table 4 ). In exon 2, the novel variant c.127A $>\mathrm{G}$ was detected in $1 \mathrm{PCa}$ blood sample (Fig. 1). Exploration of the association between HOXB13 mutation in the tissue and blood in PCa cases showed a significant reciprocal correlation ( $p=0.02$, Fig. 2).

\begin{tabular}{|c|c|c|c|c|c|}
\hline $\begin{array}{l}\text { Patient } \\
\text { Code }\end{array}$ & Location & cDNA Alteration & rs Number & Classification & Variant Type \\
\hline 1 & Exon 1 & $\begin{array}{l}\text { c. } 366 \mathrm{C}>\mathrm{T} \\
\text { c. } 513 \mathrm{~T}>\mathrm{C}\end{array}$ & $\begin{array}{c}\text { rs } 8556 \\
\text { rs9900627 }\end{array}$ & Heterozygote & Synonymous \\
\hline 4 & Exon 1 & c. $366 \mathrm{C}>\mathrm{T}$ & rs 8556 & Heterozygote & Synonymous \\
\hline 5 & Exon 1 & c. $513 \mathrm{~T}>\mathrm{C}$ & rs9900627 & Heterozygote & Synonymous \\
\hline 9 & Exon 1 & c. $513 \mathrm{~T}>\mathrm{C}$ & rs9900627 & Heterozygote & Synonymous \\
\hline 11 & Exon 1 & c. $513 \mathrm{~T}>\mathrm{C}$ & rs9900627 & Heterozygote & Synonymous \\
\hline 12 & Exon 2 & c. $728 \mathrm{~A}>\mathrm{G}$ & & Heterozygote & New Variant \\
\hline 13 & Exon 1 & c. $513 \mathrm{~T}>\mathrm{C}$ & rs9900627 & Heterozygote & Synonymous \\
\hline 15 & Exon 1 & c. $366 \mathrm{C}>\mathrm{T}$ & rs 8556 & Heterozygote & Synonymous \\
\hline 19 & Exon 1 & $\begin{array}{l}\text { c. } 366 C>T \\
\text { c. } 513 \mathrm{~T}>\mathrm{C}\end{array}$ & $\begin{array}{c}\text { rs } 8556 \\
\text { rs } 9900627\end{array}$ & Heterozygote & Synonymous \\
\hline
\end{tabular}




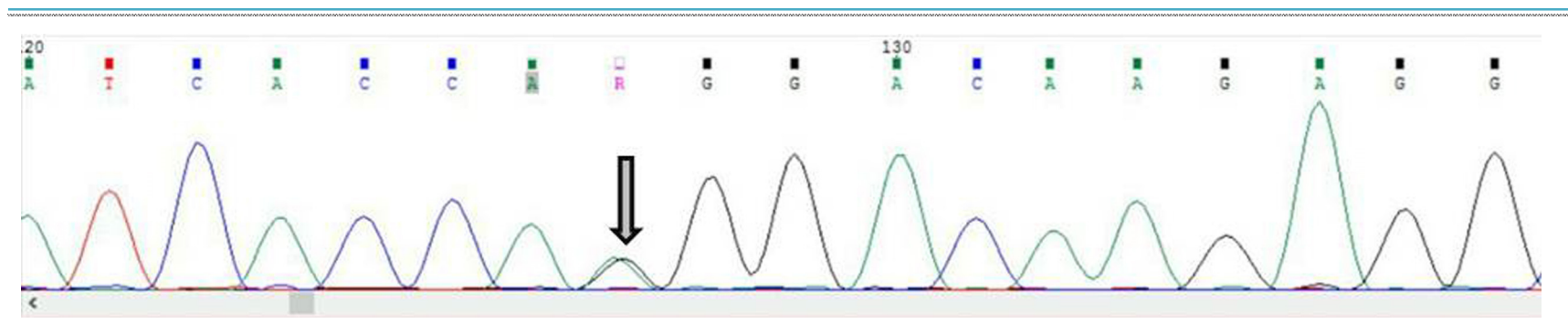

Fig. 1. The c. $728 \mathrm{~A}>\mathrm{G}$ variant in exon 2 of blood of prostate cancer $(\mathrm{Code}=12)$

The association between HOXB13 mutations with clinicopathological data

The relationship between HOXB13 mutation and clinicopathologic parameters in PCa and BPH cases was explored using chi-square test. Our analysis showed a significant association between no mutation in HOXB13 gene and low PSA level $(<4 \mathrm{ng} / \mathrm{mL})$, (chi-square $(2, \mathrm{~N}=$ $51)=11.05, \mathrm{p}=0.05)$ (Table 5). The HOXB13 gene mutation showed a marginal trend between PCa compared to $\mathrm{BPH}$ cases, $($ chi-square $(2, \mathrm{~N}=55)=5.1, \mathrm{p}=0.08)$. No significant association was found between HOXB13 gene mutation and family history and smoking (chi-square (2, $\mathrm{N}=55)=11.1, \mathrm{p}=0.18$, and chi-square $(2, \mathrm{~N}=55)=7$, $\mathrm{p}=0.89$, respectively).

\section{Discussion}

Twin studies have shown that there is a strong genetic background in the predisposing of PCa compared to other common cancers, including breast, ovarian, and colorectal cancers (15). Therefore, a large body of studies has demonstrated a correlation between genetic variations, including single nucleotide polymorphisms (SNPs), and risk of PCa (16). Homeobox B13 (HOXB13) gene is implicated in the normal formation of the urogenital tract and its dysregulation was reported as a strong candidate gene for developing PCa $(12,17,18)$.

In Iran, prostate cancer ranks the third most common fatal malignant tumor, and to the best of our knowledge there is no data regarding the analysis of HOXB13 in Iranian men. Thus, in the present study, we explored the variant(s) in $\mathrm{PCa}$ patient tissues compared to $\mathrm{BPH}$ cases (19-22). In addition, the potential variant(s) was investigated in the blood samples of PCa. All PCa tissues with mutation in HOXB13 gene (four cases) and the majority of PCa blood samples (6 out of 9 cases) had c.366C $>\mathrm{T}$ variant (rs8556). Surprisingly, our analysis revealed a novel variant c. $728 \mathrm{~A}>\mathrm{G}$ in exon 2 of $\mathrm{HOXB} 13$ in one case of PCa blood sample. In the BPH tissues with mutation, our findings indicated that there are only c.366C $>\mathrm{T}(\mathrm{rs} 8556)$ or c.513T $>\mathrm{C}(\mathrm{rs} 9900627)$ variants. The correlation between HOXB13 G84E mutation (rs138213197) and prostate cancer risk has been investigated in European populations $(23,24)$. The incidence of this mutation was reported from $1.06 \%$ in northern European populations to $1.5 \%$ in the UK, but we did not detect such mutation in Iranian men. In a study conducted by Hamid et al., evaluation of HOXB13 in prostate cancer cell lines revealed that HOXB13 has a key role in cell cycle regulation (25). Their analysis, conducted on Turkish population, also showed increased expression of HOXB13 in prostate cancer compared to non-malignant prostate tissues (25). No data on HOXB13 are available from Iraq and Pakistan for comparison.

Our findings also showed a significant correlation between HOXB13 mutation in the tissue and blood samples of PCa patients. Varinot et al. demonstrated more than $90 \%$ sensitivity for HOXB13 gene in metastatic cases of PCa (26). A previous study also indicated that HOXB13 gene had the sensitivity and specificity of $100 \%$ and $94 \%$ for $\mathrm{PCa}$, respectively (27). It can be concluded that HOXB13 may be considered as a potential marker for screening and identification of $\mathrm{PCa}$.

Table 5. Association between patient characteristics and HOXB13 gene mutation (The values shown in bold, are statistically significant)

\begin{tabular}{ll}
\hline Patient characteristics & P-value \\
\hline $\begin{array}{l}\text { Mean of age } \\
<68 \text { vs }>68\end{array}$ & 0.75 \\
PCa vs BPH & \\
PSA level & 0.08 \\
$<4$ & \\
$4-10$ & 0.05 \\
$>10$ & \\
Family history & \\
Yes vs no & 0.18 \\
Smoking inhalation & \\
Yes vs no & 0.89 \\
\hline
\end{tabular}

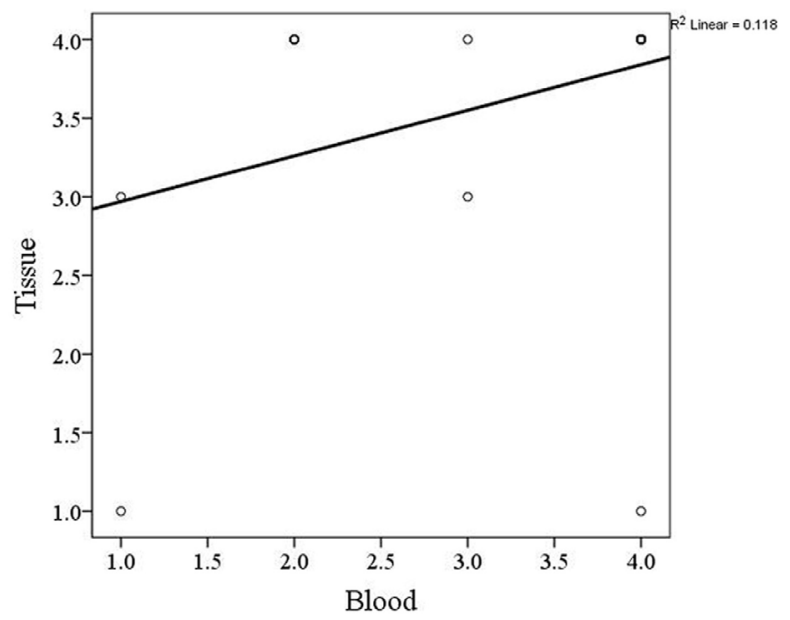

Fig. 2. The correlation between HOXB13 gene mutation in tissue and blood specimens of prostate cancer patients

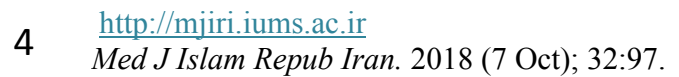


Screening HOXB13 mutations in a large population of Iranian men is suggested. Analysis of HOXB13 expression at the levels of both gene and protein could shed light on cellular and molecular aspects of the function of this gene in prostate cancer tumorigenesis. Also, evaluation of HOXB13 along with other prostate cancer susceptibility genes, including BRCA1, BRCA2, and androgen receptor (AR), is warranted.

\section{Conclusion}

Variations were found in the BPH samples in exon 1, but not in exon 2. The variants in exon 2 of HOXB13 may influence prostate cancer susceptibility. Furthermore, evaluation of HOXB13 mutation may be considered as a novel marker for screening PCa. Further investigations are warranted to evaluate the clinical significance of HOXB13 in Iranian population.

\section{Acknowledgments}

None.

\section{Human participants}

All procedures were in accordance with the ethical standards of the responsible committee on human experimentation (institutional and national) and with the Helsinki Declaration of 1975, as revised in 2000 (5). Informed consent was obtained from all patients.

\section{Conflict of Interests}

The authors declare that they have no competing interests.

\section{References}

1. Siegel RL, Miller KD, Jemal A. Cancer statistics, 2015. CA Cancer J Clin. 2015;65(1):5-29.

2. Jemal A, Siegel R, Xu J, Ward E. Cancer statistics, 2010. CA Cancer J Clin. 2010;60(5):277-300.

3. Kahlem P, Dörken B, Schmitt CA. Cellular senescence in cancer treatment: friend or foe? J Clin Invest. 2004;113(2):169-74.

4. Kim YR, Oh KJ, Park RY, Xuan NT, Kang TW, Kwon DD, et al. HOXB13 promotes androgen independent growth of LNCaP prostate cancer cells by the activation of E2F signaling. Mol Cancer. 2010;9(1):124.

5.Decker B, Ostrander EA. Dysregulation of the homeobox transcription factor gene HOXB13: role in prostate cancer. Pharmgenomics Pers Med. 2014;7:193.

6. Bhatlekar S, Fields JZ, Boman BM. HOX genes and their role in the development of human cancers. J Mol Med (Berl). 2014;92(8):81123.

7. Ewing CM, Ray AM, Lange EM, Zuhlke KA, Robbins CM, Tembe $\mathrm{WD}$, et al. Germline mutations in HOXB13 and prostate-cancer risk. N Engl J Med. 2012;366(2):141-9.

8. Akbari MR, Trachtenberg J, Lee J, Tam S, Bristow R, Loblaw A, et al. Association between germline HOXB13 G84E mutation and risk of prostate cancer. J Natl Cancer Inst. 2012;104(16):1260-2.

9. Breyer JP, Avritt TG, McReynolds KM, Dupont WD, Smith JR. Confirmation of the HOXB13 G84E germline mutation in familial prostate cancer. Cancer Epidemiol Biomarkers Prev. 2012;21(8): 1348-53.

10.Chen Z, Greenwood C, Isaacs WB, Foulkes WD, Sun J, Zheng SL, et al. The G84E mutation of HOXB13 is associated with increased risk for prostate cancer: results from the REDUCE trial. Carcinogenesis. 2013;34(6):1260-4

11.Lin X, Qu L, Chen Z, Xu C, Ye D, Shao Q, et al. A novel germline mutation in HOXB13 is associated with prostate cancer risk in Chinese men. Prostate. 2013;73(2):169-75.
12.Zabalza CV, Adam M, Burdelski C, Wilczak W, Wittmer C, Kraft S, et al. HOXB13 overexpression is an independent predictor of early PSA recurrence in prostate cancer treated by radical prostatectomy. Oncotarget. 2015;6(14):12822-34.

13.Edwards SE, Flohr P, Clark J, Campbell C, Rogers S, Kovacs G, et al. HOXB13-a potential marker for prostate cancer. AACR; 2005.

14.Zhang J, Xiao L, Qin Z, Xu A, Zhao K, Liang C, et al. Association between germline homeobox B13 (HOXB13) G84E allele and prostate cancer susceptibility: a meta-analysis and trial sequential analysis. Oncotarget. 2016;7(41):67101.

15.Lichtenstein P, Holm NV, Verkasalo PK, Iliadou A, Kaprio J, Koskenvuo M, et al. Environmental and heritable factors in the causation of cancer-analyses of cohorts of twins from Sweden, Denmark, and Finland. N Engl J Med. 2000;343(2):78-85.

16.Goh C, Schumacher F, Easton D, Muir K, Henderson B, Kote-Jarai $\mathrm{Z}$, et al. Genetic variants associated with predisposition to prostate cancer and potential clinical implications. J Intern Med. 2012;271(4):353-65.

17.Schroeck FR, Zuhlke KA, Siddiqui J, Siddiqui R, Cooney KA, Wei JT. Testing for the recurrent HOXB13 G84E germline mutation in men with clinical indications for prostate biopsy. $J$ Urol. 2013;189(3):849-53.

18.Stott-Miller M, Karyadi DM, Smith T, Kwon EM, Kolb S, Stanford $\mathrm{JL}$, et al. HOXB13 mutations in a population-based, case-control study of prostate cancer. Prostate. 2013;73(6):634-41.

19.Kalantari E, Saadi FH, Asgari M, Shariftabrizi A, Roudi R, Madjd Z. Increased Expression of ALDH1A1 in Prostate Cancer is Correlated With Tumor Aggressiveness: A Tissue Microarray Study of Iranian Patients. Appl Immunohistochem Mol Morphol. 2017 ;25(8):592-598.

20.Roudi R, Ebrahimi M, Shariftabrizi A, Madjd Z. Cancer stem cell research in Iran: potentials and challenges. Future Oncol. 2017 ;13(20):1809-1826.

21.Foroozan M, Roudi R, Abolhasani M, Gheytanchi E, Mehrazma M. Clinical significance of endothelial cell marker CD34 and mast cell marker CD117 in prostate adenocarcinoma. Pathol Res Pract. 2017;213(6):612-8.

22.Pakzad R, Rafiemanesh H, Ghoncheh M, Sarmad A, Salehiniya H, Hosseini S, et al. Prostate Cancer in Iran: Trends in Incidence and Morphological and Epidemiological Characteristics. Asian Pac J Cancer Prev. 2016;17(2):839-43.

23.Laitinen VH, Wahlfors T, Saaristo L, Rantapero T, Pelttari LM, Kilpivaara O, et al. HOXB13 G84E mutation in Finland: populationbased analysis of prostate, breast, and colorectal cancer risk. Cancer Epidemiol Biomarkers Prev. 2013;22(3):452-60.

24.Kote-Jarai Z, Mikropoulos C, Leongamornlert D, Dadaev T, Tymrakiewicz M, Saunders E, et al. Prevalence of the HOXB13 G84E germline mutation in British men and correlation with prostate cancer risk, tumour characteristics and clinical outcomes. Ann Oncol. 2015;26(4):756-61.

25.Hamid SM, Cicek S, Karamil S, Ozturk MB, Debelec-Butuner B, Erbaykent-Tepedelen B, et al. HOXB13 contributes to $\mathrm{G} 1 / \mathrm{S}$ and G2/M checkpoint controls in prostate. Mol Cell Endocrinol. 2014;383(1-2):38-47.

26. Varinot J, Furudoï A, Drouin S, Phe V, Penna RR, Roupret M, et al. HOXB13 protein expression in metastatic lesions is a promising marker for prostate origin. Virchows Arch. 2016;468(5):619-22.

27.Barresi V, Ieni A, Cardia R, Licata L, Vitarelli E, Reggiani Bonetti $\mathrm{L}$, et al. HOXB13 as an immunohistochemical marker of prostatic origin in metastatic tumors. APMIS. 2016;124(3):188-93. 